\title{
How much will it cost to scale up a reproductive health pilot project?
}

Barbara Janowitz

John H. Bratt

Rick Homan

James R. Foreit

Population Council

Follow this and additional works at: https://knowledgecommons.popcouncil.org/departments_sbsr-rh

Part of the Demography, Population, and Ecology Commons, Family, Life Course, and Society Commons, International Public Health Commons, and the Medicine and Health Commons How does access to this work benefit you? Let us know!

\section{Recommended Citation}

Janowitz, Barbara, John H. Bratt, Rick Homan, and James R. Foreit. 2007. "How much will it cost to scale up a reproductive health pilot project?" FRONTIERS Program Brief no. 8. Washington, DC: Population Council. 


\section{How Much Will lt Cost to Scale Up a Reproductive Health Pilot Project?}

$M$ ost service delivery interventions begin as pilot projects. When a pilot study of an intervention is successful, managers begin to think about scaling up the project to new areas. Cost is a critical factor influencing the extent and pace of scale-up. This brief explains how to adapt and modify cost information obtained from a pilot project to estimate scaleup costs. The brief shows why the costs of a pilot project alone are not sufficient to predict costs of scale-up, and gives examples of how costs are influenced by factors like economies and diseconomies of scale, resource substitution, and intervention modification. The purpose of the brief is not to provide a "cookbook" for estimating scale-up costs. Rather, it is designed to help managers think critically about the factors that must be considered in estimating the costs of scaling up an effective intervention.

This brief discusses factors that program managers need to consider when scaling up pilot projects. The first decision is whether to scale up the pilot project at all. There should be evidence that the pilot project proved successful and its success should be achieved at reasonable cost. Not all pilot projects are can- didates for scale-up, either because they are found to be ineffective or because they are not affordable; in other words, they have low cost effectiveness. ${ }^{1}$

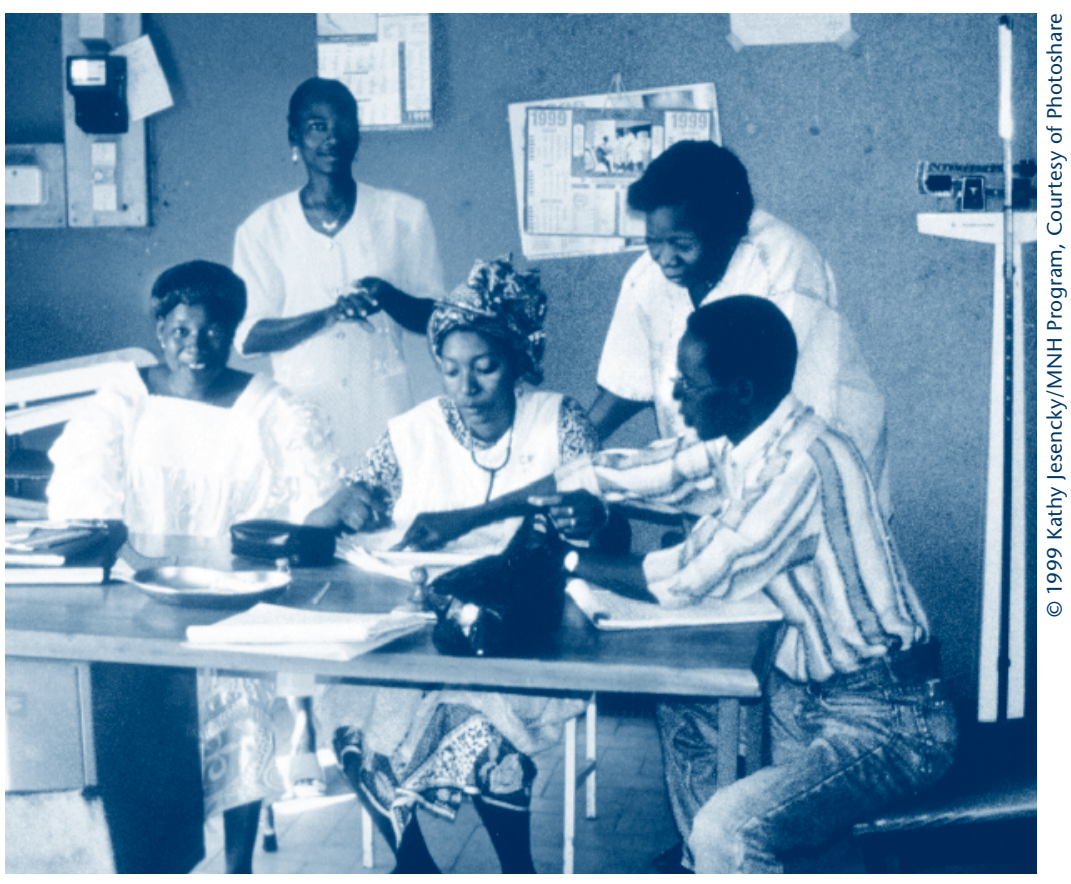

Costs in the scale-up phase may vary from those in a pilot project.

- Factors such as changes in scale, modifications of the intervention, and personnel allocation can influence scale-up costs.

- Consider scale-up costs before designing the pilot intervention. 


\begin{abstract}
Frontiers in Reproductive Health Program Brief No. 8

Authors: Barbara Janowitz, John Bratt, Rick Homan, and Jim Foreit

Editors: Laura Raney Sarah Campbell

Design: Vincent Hughes Visualization

The assistance of the following reviewers is appreciated: Ian Askew and Patricia Stephenson.

The photos on pages 1,5 , and 10 were selected from Photoshare at www.photoshare.org.

Understanding the factors that affect the costs of scaling up will encourage better decisions about the extent and pace of the scale-up. The term "scaling up" may be used to describe several different methods of expanding a program; this brief uses the term to indicate expansion of a pilot project to new locations. ${ }^{2}$ Although the examples in this brief are drawn from a reproductive health project, the principles discussed apply to other types of health projects as well.
\end{abstract}

Suggested citation: Janowitz, Barbara, John Bratt, Rick Homan, and Jim Foreit. 2007. "How much will it cost to scale up a reproductive health pilot project?" FRONTIERS Program Brief No. 8. Washington, DC: Population Council.

The Frontiers in Reproductive Health Program (FRONTIERS) applies systematic research techniques to improve delivery of family planning and reproductive health services and influence related policies. FRONTIERS is funded by the US Agency for International Development (USAID) and led by the Population Council in collaboration with Family Health International.

This publication is made possible by the generous support of the American people through the United States Agency for International Development (USAID) under the terms of Cooperative Agreement No. HRN-A-00-98-00012-00. The contents are the responsibility of the FRONTIERS Program and do not necessarily reflect the views of USAID or the United States Government.

C 2007 The Population Council, Inc.

This publication may be reproduced in whole or in part without permission of Population Council provided full source citation is given and the reproduction is not for commercial purposes.

ISSN 1546-6612

\section{Organizations often track costs} of interventions in pilot projects. While it may seem logical to simply extrapolate those costs to additional sites, the relationship between costs in a pilot project and costs in a scale-up is not so straightforward. The costs of serving a large population will probably not be a simple proportional increase in the costs of the pilot project. However, with some adjustments, the costs of the pilot project can be used to estimate scale-up costs.

\section{The relationship between resources and outcomes}

To estimate costs we use the simple logic model shown in Figure 1. Inputs or resources, through a series of activities, are used to produce outputs, which in turn lead to the desired outputs. Activities require inputs such as labor (curriculum designers, trainers, supervisors, clinicians); capital (buildings, audio visual equipment, examining room tables) and materials (contraceptives, gasoline, meals) that are used to carry out activities that, in turn, produce program outputs. Costs are calculated by multiplying the amount of each input by its price (for example, the hours of clinician labor by clinician workers' wage rate) and then summing up all inputs. Cost effectiveness analysis involves a comparison of

\section{Contents}
The relationship between resources and outputs

Why scale-up costs differ from pilot costs
Estimating scale-up costs: An example from Egypt
Costs and decisions on scale-up 10

Conclusion 11 
Figure 1.

The model to estimate costs of scaling up

\begin{tabular}{|c|c|c|c|}
\hline Inputs & Activities & Outputs & Outcomes \\
\hline $\begin{array}{l}\text { Labor } \\
\text { Equipment } \\
\text { Materials }\end{array}$ & $\begin{array}{l}\text { Planning } \\
\text { - Design intervention } \\
\text { — Brainstorming meetings } \\
\text { n Design intervention } \\
\text { Implementation of } \\
\text { Intervention } \\
\text { - Train personnel } \\
\text { - Upgrade facilities } \\
\text { Service Delivery } \\
\text { - Providers talk more } \\
\text { about side effects, etc; } \\
\text { - Offer clients more } \\
\text { services }\end{array}$ & 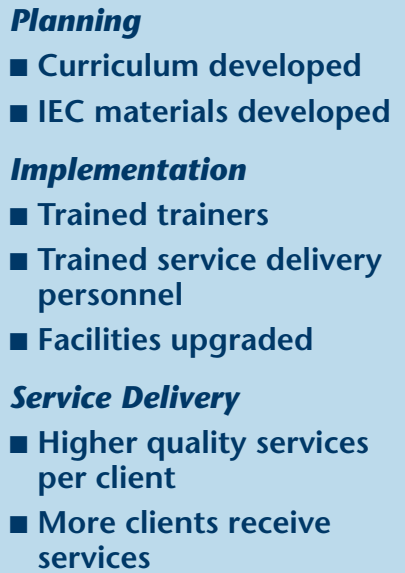 & $\begin{array}{l}\text { Higher contraceptive use } \\
\text { Higher continuation rates }\end{array}$ \\
\hline
\end{tabular}

achieved outcomes (for example higher continuation rates among contraceptive acceptors) with cost. Thus the logic model provides a framework for conducting cost-effectiveness analysis as well as the costs of scaling up.

It is important to recognize that all resources have costs, regardless of who pays for them. When a program uses an input that it purchased, this is called a "financial cost." But when a program uses an input purchased by some other entity (i.e., a donor), this is called a "non-financial cost." Non-financial costs are also called "economic costs." It is important to include costs of all inputs in the scale-up estimate, not just financial costs. We do this because programs acquire and use resources in different ways, and these may change throughout scale-up. For example, labor requirements in the scale-up may initially be met by redeploying underutilized staff, but eventually it is possible that financial costs will increase as new labor is hired.

In the next section, we consider scale-up costs for a particular project. The costs are specific to that project. While all inputs may be characterized as labor, supplies or capital, different projects may use different types of these inputs. For example, in an educational intervention, counseling may be provided by teachers and peer educators, while in a community outreach program services may be provided by community workers at their homes or at the homes of their clients.

\section{The relationship between costs in a pilot project and costs in a scale-up is not likely to be straightforward.}

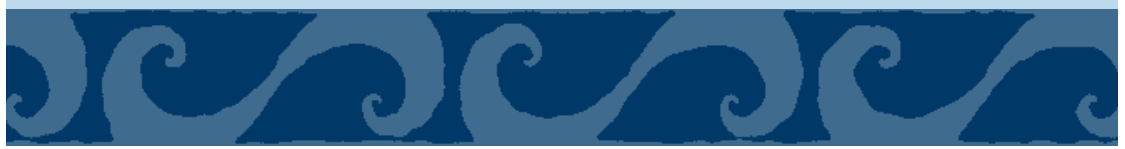




\section{Why scale-up costs differ from pilot costs}

Suppose your organization spent $\$ 100,000$ to implement a pilot project in one hospital. Based upon the favorable results (i.e., effectiveness), the Ministry of Health is interested in expanding the intervention to 10 additional hospitals. If you were asked to estimate the costs of scaleup, the simplest answer would be $\$ 1$ million $(10 \times \$ 100,000)$. This section explains why that estimate is unlikely to be accurate.

Costs in a scale-up may vary from those in a pilot project for several reasons (see box).

\section{Number and size of service delivery points}

The larger the scale-up, the higher the total costs. But the cost per service delivery point (SDP) depends on the number and size of service delivery points. Increasing the number of SDPs may create opportunities to reduce the average cost per SDP. For example, if urban clinics are added in the scale-up of a pilot project, it may be possible to train staff from a greater number of clinics in a single training session. The cost of the trainer can then be spread across a greater number of SDPs and this reduces the average cost per clinic. Economists refer to this phenomenon as "economies of scale." However, if fewer clinics were included in each training session than in the pilot program because the program

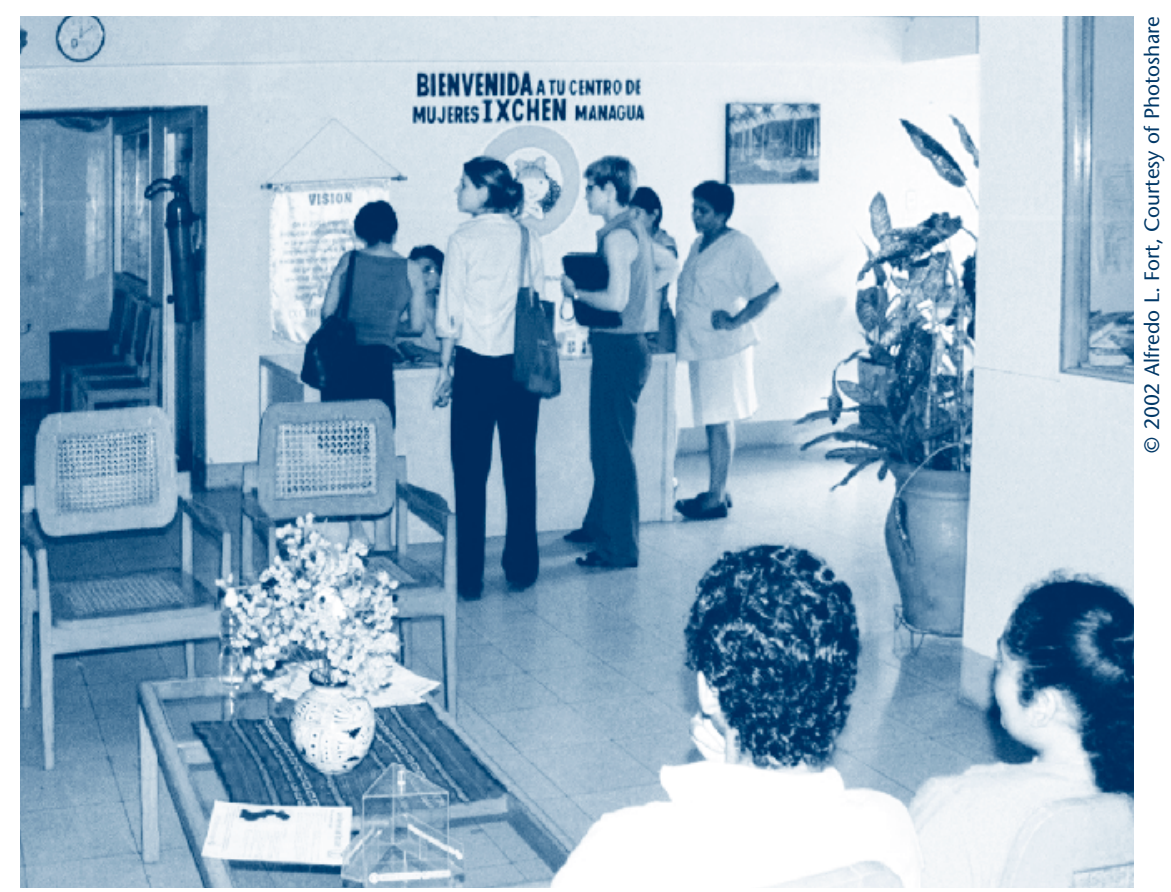

was expanding to rural sites, then training costs per clinic would increase ("diseconomies of scale").

If the new SDPs serve more clients than the SDPs in the pilot program, then more supplies per clinic will be used in the scaleup and the cost per clinic will be greater. If the new SDPs have lower client volumes, then fewer supplies per clinic will be used, and the cost per clinic will be lower. However, with more clients, the cost per client is likely to decrease. While the cost of supplies per client is unlikely to change, clinic labor and capital will be spread over a larger number of visits so that the cost per client will be lower.
Who provides the resources? Scale-up costs might also differ from those in the pilot project if the scale-up is carried out by a different organization than the one that paid for the pilot project. Donor-funded pilot projects typically include many activities carried out by contractors, cooperating agencies, or international consultants. When projects are scaled up, responsibility for these activities may be assumed by local organizations or government agencies such as the Ministry of Health $(\mathrm{MOH})$. Using different sources for inputs can affect costs of activities and outputs in various ways.

For example, consider a pilot project in which an international donor contracts with a local forprofit group to develop a training curriculum on quality of care 
and to conduct trainings of trainers and intervention personnel. In the scale-up, suppose these tasks are taken over by the $\mathrm{MOH}$. If the scale-up is large, the $\mathrm{MOH}$ may need to hire new trainers, which would add to the total cost of this activity. However, the price of inputs (wages of the new trainers) is likely to be lower in the scale-up because the salaries of ministry employees are generally lower than those of employees in a contracted organization.

Depending on the size of the scale-up, the $\mathrm{MOH}$ might be able to use the time of trainers already on its payroll. This option might appear attractive to $\mathrm{MOH}$ decision makers because there would not be additional financial costs associated with hiring new staff. However, using these staff for the family planning scale-up training reduces their availability to undertake other productive activities. For example, if staff assigned to do the family planning training had previously been training others in malaria eradication or tuberculosis treatment, these activities now would be sacrificed for the sake of the family planning program scale-up. So even though there is no financial outlay, there is an "opportunity cost" — which is the value of an opportunity that is lost when the choice of one course of action requires that another course of action be given up. If decision makers do not recognize opportunity

\section{With some adjustments, the costs of the pilot project can be used to estimate scale-up costs.}

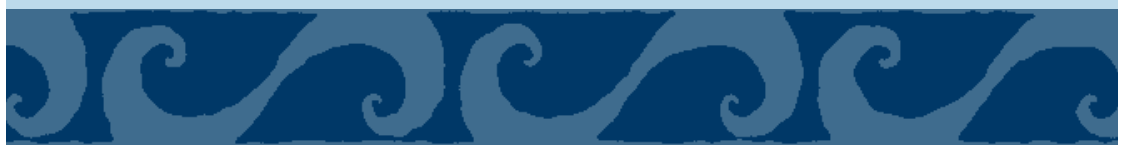

costs, they risk underestimating the true cost of an activity. In the example above, diverting staff from malaria eradication and tuberculosis treatment may have zero financial cost for the family planning scale-up, but if malaria eradication and tuberculosis treatment training still were needed, the $\mathrm{MOH}$ would have to hire additional staff at a later date.

\section{Changes in the intervention}

If some components of the pilot project prove more effective than others, decision-makers may change the intervention to emphasize these components in the scale-up. Such changes likely

\section{Factors affecting the cost per service delivery point of scaling up}

number and size of service delivery points

Who provides the resources

- Prices of inputs

- Financial and nonfinancial costs

Changes in the intervention

- Output mix

- Number and intensity of activities will affect costs. For example, in a youth-related pilot project carried out by FRONTIERS, youth were encouraged to visit clinics more frequently, and teachers were requested to increase time teaching and counseling youth about reproductive health. If the scale-up were to emphasize the clinic-based intervention over increased counseling by teachers, more training sessions for nurses and physicians would be required (and fewer trainings for teachers), which probably would affect costs.

The scale-up may also differ from the pilot project in the number and intensity of intervention activities. For example, if additional officials need to be sensitized to the intervention, or if the training curriculum needs to be revised, costs of these activities will be higher than in the pilot project. On the other hand, if all stakeholders were already informed about the intervention, and the training curriculum did not need modification, there would be few or no costs for this part of the expansion. 


\section{Estimating scale-up costs: An example from Egypt}

In this section, we use information from a reproductive health project that FRONTIERS carried out in Egypt to estimate the costs of a hypothetical scale-up. The goal of the FRONTIERS project was to improve contraceptive continuation by enhancing the interactions between clients and providers. Inputs (labor, equipment, and materials), through a series of activities, were used to produce outputs, such as a training curriculum; information, education, and communication (IEC) materials; training sessions; and, ultimately, better clientprovider interactions. Figure 2 provides more detail on the components of the pilot project.

The project was conducted in 24 clinics, for a total cost of
US\$100,339. Table 1 shows a breakdown of the project's costs by phase.

In our example, the project is expanded to cover an additional 567 clinics in the governorates. If we assume that the cost per clinic was the same in the pilot as in the scale-up, the estimated cost of scaling up would be US $\$ 4,181$ times 567 , or $\$ 2,370,627$. This assumes (1) that the scale-up

Figure 2.

\section{Factors affecting the cost per service delivery} point of scaling up

\begin{tabular}{|c|c|c|c|}
\hline Inputs & Activities & Outputs & Outcomes \\
\hline $\begin{array}{l}\text { Labor } \\
\text { Equipment } \\
\text { Materials }\end{array}$ & 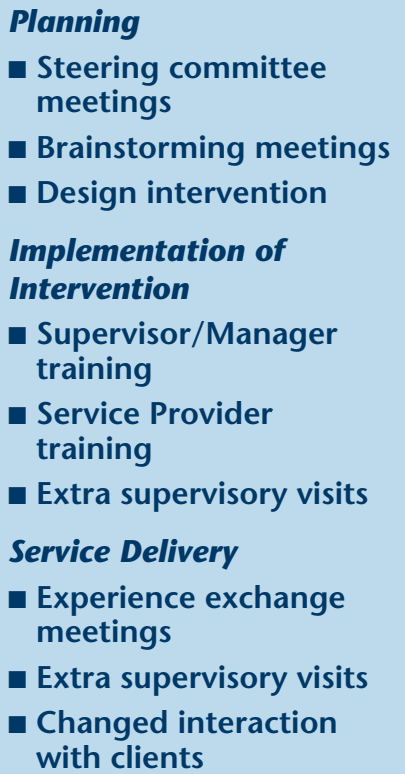 & $\begin{array}{l}\text { Planning } \\
\text { n Curriculum developed } \\
\text { - IEC materials developed } \\
\text { Implementation } \\
\text { - Trained supervisors and } \\
\text { managers } \\
\text { - Trained service delivery } \\
\text { personnel } \\
\text { - Reinforced training } \\
\text { through supervision } \\
\text { Service Delivery } \\
\text { - Visits with improved } \\
\text { client-provider interaction }\end{array}$ & - Higher continuation rates \\
\hline
\end{tabular}


intervention (steering committee, brainstorming), savings per clinic would be substantial.

Based on estimates of which planning activities from the pilot project would need to be repeated, we estimated that total planning costs for 567 clinics would be about the same, even though the number of clinics would increase almost 24-fold (Table 2).

Planning costs would be even lower if, as expected, the $\mathrm{MOH}$ were to play a larger role in the scale-up and if the $\mathrm{MOH}$ were to redeploy existing staff to new tasks. Even if the $\mathrm{MOH}$ needed to hire new staff members, planning costs per clinic would be lower in the scale-up, as salaries of $\mathrm{MOH}$ personnel are likely to be lower than those of the pilot project's contractors. However, we did not factor the potential costs savings of using local labor into this example.

\section{Implementation of the plan} Implementation includes costs associated with putting in place the plan developed in phase one of the pilot project. Thus providers would be trained in the curriculum developed in the planning stage and the supervisors and managers would be trained so that they could reinforce the service provider training. While most of the activities in the planning phase should not have to be repeated as a pilot project expands to new clinics in areas covered by the pilot project, almost all of the activities in the implementation phase will need

Table 2.

\section{Planning costs of the pilot project compared to scale-up}

\begin{tabular}{lll} 
& $\begin{array}{l}\text { Pilot project } \\
(24 \text { clinics })\end{array}$ & $\begin{array}{l}\text { Scale-up } \\
(567 \text { clinics })\end{array}$ \\
\hline Total cost & $\$ 24,420$ & $\$ 22,587$ \\
Cost per clinic & $\$ 1,018$ & $\$ 40$ \\
\hline
\end{tabular}

to be repeated. For example, providers in the new clinics will need to be trained.

In many projects, training accounts for a large share of implementation costs in pilot projects. Training costs include expenses for all training of trainers, training of intervention personnel, training venue, equipment rental, hotel and meal expenses, and travel. ${ }^{3}$

The pilot project in Egypt included three clinics in each of the training sessions, but in this scaleup example, we have increased the number of clinics included in each session to four. Thus, there would be 142 sessions for 567 clinics instead of 189 sessions $(567 \div 3)$. As shown in Table 3 ,

Table 3.

\section{Training costs of providers in the} pilot project and in the scale-up

\begin{tabular}{lll} 
& $\begin{array}{l}\text { Pilot project } \\
(24 \text { clinics) }\end{array}$ & $\begin{array}{l}\text { Scale-up } \\
\text { (567 clinics) }\end{array}$ \\
Total costs & $\$ 7,528$ & $\$ 132,571$ \\
Costs per clinic & $\$ 314$ & $\$ 234$ \\
\hline
\end{tabular}

training costs per clinic are about one-quarter less than if we had simply multiplied the per-clinic cost by the number of clinics targeted for the scale-up. The perclinic scale-up costs are reduced because the scale-up takes advantage of having more service delivery points in each training session (economies of scale).

\section{Supervision}

Pilot projects often involve more supervision visits to ensure that the intervention is implemented as designed. If the pilot project's budget provides supervisors with additional funds for travel and per diems, then these additional costs must be taken into consideration in the scale-up. 


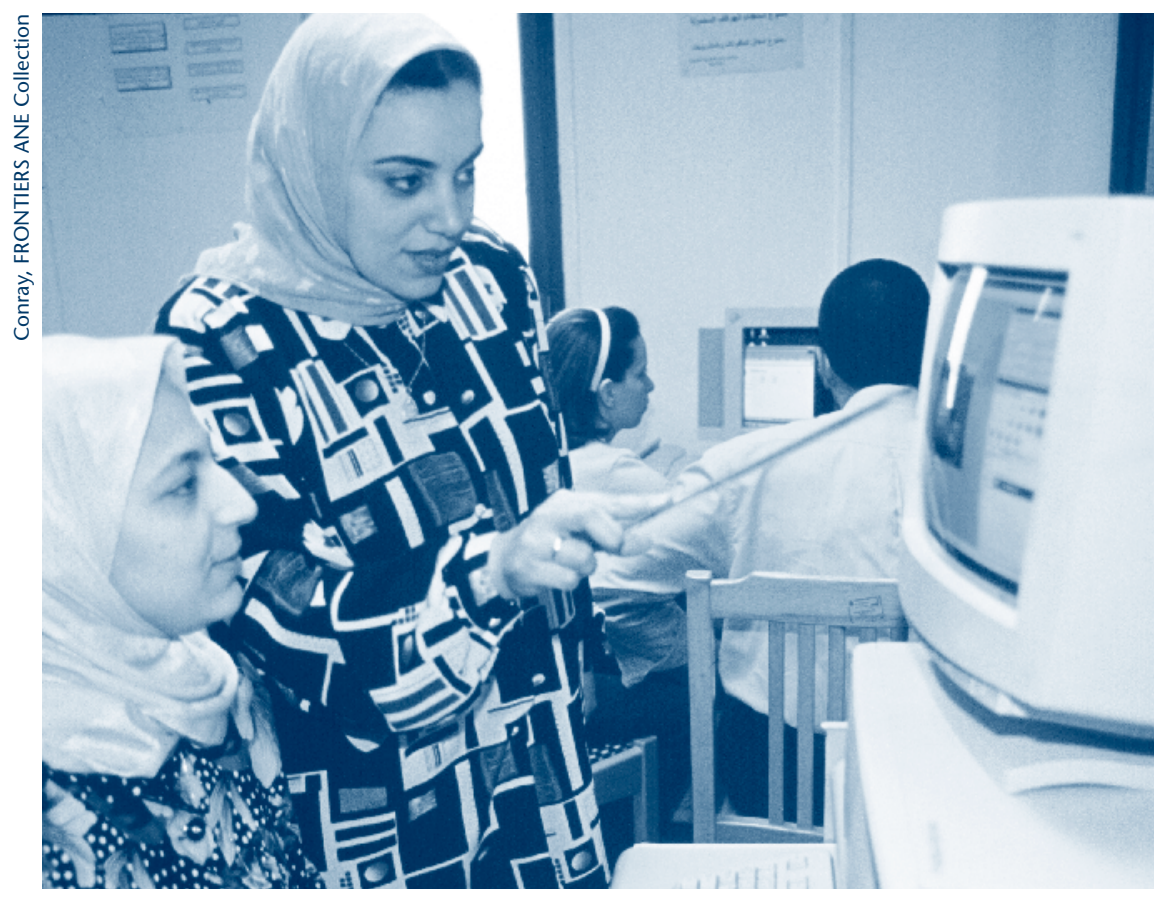

During the implementation phase in the 24 clinics, $\$ 24,793$ was spent on supervision or $\$ 1,033$ per clinic. This cost was incurred to support the salaries of the contractor's staff as well as the per diems and other travel expenses of $\mathrm{MOH}$ and contractor staff when they were engaged in making these additional visits. If supervision in the expanded project were to involve the same number of visits to each clinic to make sure that the intervention was implemented as planned, the cost would be determined by a simple multiplier (Table 4).

\section{Service delivery}

Improving client-provider interactions is often associated with longer client contacts. As a consequence, total contact time with clients might increase and new staff might need to be hired. If a project lacks resources to hire more staff, and if clinics are working at full capacity,

Table 4.

Supervision costs in the implementation phase of the pilot project and in the scale-up

\begin{tabular}{lll} 
& $\begin{array}{l}\text { Pilot project } \\
(24 \text { clinics })\end{array}$ & $\begin{array}{l}\text { Scale-up } \\
(567 \text { clinics })\end{array}$ \\
Total costs & $\$ 24,793$ & $\$ 585,711$ \\
Costs per clinic & $\$ 1,033$ & $\$ 1,033$ \\
\hline
\end{tabular}

contact time could be increased by shifting providers from a task to a client-contact or by decreasing the number of clients. Both solutions, however, entail opportunity costs of (1) the sacrifice of whatever providers stopped doing in order to spend more time with clients and (2) a decrease in number of clients served, respectively. In many instances, however, clinics are not at full capacity and providers could shift unused time to contact time, so that no additional cost would be incurred. However, it is important to note that it may not be easy to increase the amount of time that providers spend with clients. 4

Results from the Egyptian pilot project show that the intervention actually did not increase the time that providers spent with clients. Moreover, providers spent only a small proportion of their time with clients so that if contact time actually had increased, providers could easily have accommodated the additional time with no additional labor costs. Thus, we may conclude that there would be no additional labor costs associated with improved service delivery. ${ }^{5}$ Assuming that the clinics in the pilot study are typical of clinics in Egypt, we expect that these findings could be generalized in the scale-up.

Of course, not all clinics in developing countries are underutilized; some interventions might require significant increases in personnel time. In busy clinics, there may be little unallocated 
time to shift from one type of service provision to another. In such cases, managers must decide whether to hire a new staff person immediately or wait and determine if the demand for services is sustained to ensure that a new staff member would be reasonably busy.

During this phase, there were additional supervisory visits made to the clinics over and above the usual number, but the number of these visits was lower than in the implementation phase. For the 24 clinics, the cost was $\$ 7,191$ per clinic. We have ignored these costs in the scaleup under the assumption that these additional visits would not be made. However, the quality of care could be negatively affected by failure to make these additional visits.

\section{Costs and decisions on scale-up}

Costs should be estimated before a decision is made to scale up a pilot project, and decisionmakers should consider the following issues, whether estimating costs prior to a pilot or after it is completed.

- Planning: What elements of the pilot project's planning phase must be incorporated into the scale-up without change? Which, if any, activities require modification and which can be forgone?

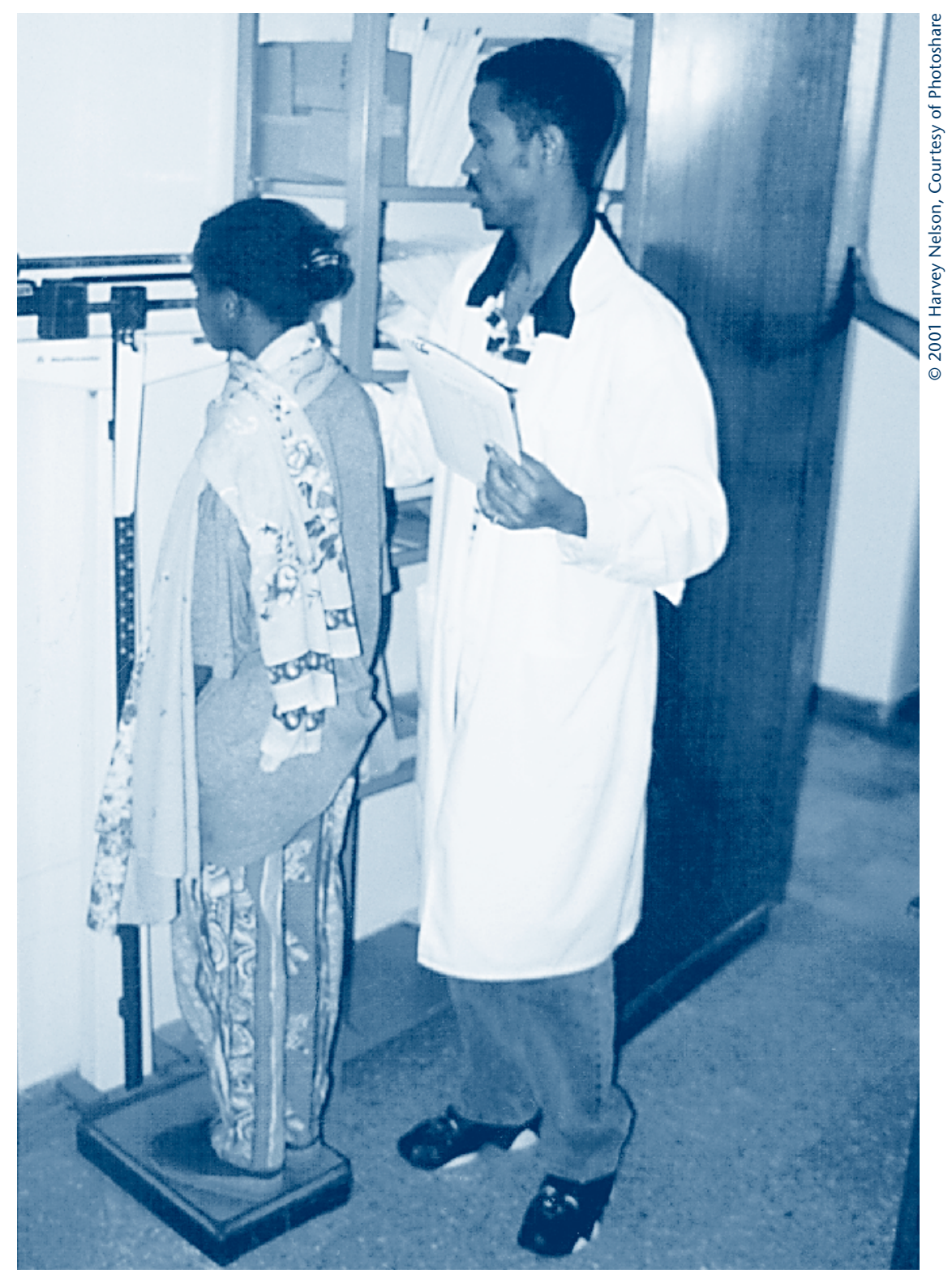

- Implementation: How many clinics can be included in each training session without compromising quality? How do the salaries of the trainers in the scale-up compare with those in the pilot project?

\section{- Service provision: Clinics in} the scale-up may have a different mix and number of clients than those in the pilot project. Will new staff members be needed, or can existing staff allocate time to the new services? How will scaling up affect the supply requirements of the clinics and are there sufficient stocks to support this level of service provision?

\section{- Monitoring and supervision} visits: Will the scale-up use the same number of visits as the pilot project did, or will the scale-up reduce these visits? If the number is reduced, will the effectiveness of the scale-up be reduced? 


\section{Consider scale-up costs before the pilot}

Thus, prior to conducting a pilot project, it is always wise to think about how the intervention would be scaled up if successful. The value of such an exercise is that the pilot project can be modified or even abandoned prior to implementation if scaleup costs are excessive. Projecting costs prior to the pilot obviously will not produce an estimate as accurate as a projection of costs conducted after the pilot is completed because it will be based on the budgeted rather than the actual costs of the pilot. Also, it will have to assume a level of output (e.g., number of client visits) that may be greater or less than actually achieved during the pilot. Hence, potential costs should be varied and more than one projection made to yield an estimated cost range rather than a single cost.

The same procedures that are used to estimate scale-up costs after completion of a pilot are used in estimating scale-up costs before the pilot is launched.

Potential economies and diseconomies of scale, differing resource costs, and opportunity costs need to be taken into consideration. Costs used in the projection should be based on the cost of the inputs of the organization that will do the scale-up. Finally, accuracy of the projection can be improved by discussing the different levels of activities that are feasible (e.g., reducing supervision visits, increasing the number of trainees per training session) for the organization doing the scaling up.

\section{Conclusion}

The lesson for both those conducting a pilot project and for those responsible for its scaleup is that they test and implement only those interventions that they can afford to scale up. There is no point in testing interventions that are not affordable. When designing a pilot project, planners should attempt to estimate the costs of scaling up before embarking on the planning phase. In so doing, the waste associated with piloting unsustainable interventions can be avoided. It may be that affordable interventions produce less spectacular results during the pilot phase, but being able to scale up more modest, affordable interventions will make a larger health impact than will small pilots that yield large health benefits for a short time only.

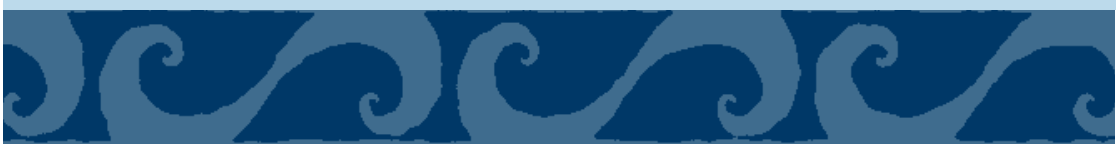

\section{Notes}

1 The essence of cost-effectiveness analysis is a comparison of costs and effectiveness measured in terms of achieved outcomes or impacts. (Drummond, Michael L. et al. 1997. Methods for the Economic Evaluation of Health Care Programmes. New York: Oxford Medical Publications and Gold, Marthe R. (ed.) et al. 1996. Cost-Effectiveness in Health and Medicine. New York: Oxford University Press.)

2 For a discussion of models of scale-up, see Cooley, Larry and Richard Kohl. 2005 "2005. "Scaling Up_From Vision to Largescale Change: A Management Framework for Practitioners." Washington, DC: Management Systems International.

3 Other implementation costs, including those for materials and other activities, are excluded from this example but are included in Table 1.

4 See Janowitz, Barbara. 2006. "Making better use of provider time in reproductive health clinics," FRONTIERS Program Brief No. 7. Washington, DC: Population Council for additional information on the difficulty of increasing the amount of time providers spend with clients.

5 Social Planning Analysis and

Administration Consultants (SPAAC). 2002. "Impact of improved client-provider interaction on women's achievement of fertility goals," FRONTIERS Report. Washington, DC: Population Council.

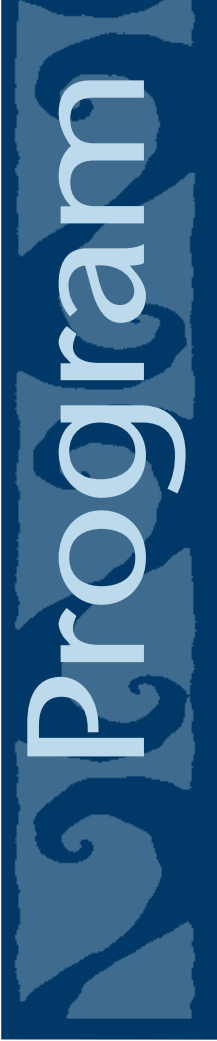


The Population Council is an international, nonprofit, nongovernmental institution that seeks to improve the well-being and reproductive health of current and future generations around the world and to help achieve a humane, equitable, and sustainable balance between people and resources. The Council conducts biomedical, social science, and public health research and helps build research capacities in developing countries. Established in 1952, the Council is governed by an international board of trustees. Its New York headquarters supports a global network of regional and country offices.

The Frontiers in Reproductive Health Program (FRONTIERS) applies systematic research techniques to improve delivery of family planning and reproductive health services and influence related policies. FRONTIERS is funded by the US Agency for International Development (USAID) and led by the Population Council in collaboration with Family Health International.

Frontiers in Reproductive Health Program (FRONTIERS) Population Council

4301 Connecticut Avenue, NW, Suite 280

Washington, DC 20008

Telephone: (202) 237-9400

Facsimile: (202) 237-8410

E-mail: frontiers@pcdc.org

www.popcouncil.org/frontiers

This publication is made possible by the generous support of the American people through the United States Agency for International Development (USAID) under the terms of Cooperative Agreement No.

HRN-A-00-98-00012-00. The contents are the responsibility of the FRONTIERS Program and do not necessarily reflect the views of USAID or the United States Government.

(c) 2007 The Population Council, Inc.

This publication may be reproduced in whole or in part without permission of Population Council provided full source citation is given and the reproduction is not for commercial purposes. 